\title{
Coprological Prevalence and Associated Risk Factors of Bovine Fasciolosis in and Around Zenzelma, Bahir Dar, Ethiopia
}

\author{
Simegn Legesse ${ }^{1}$, Solomon Tsegaye ${ }^{1 *}$, Sewagegn Lamesgen ${ }^{2}$, Yohannes Wolelaw ${ }^{3}$, Dilip Garikipati ${ }^{2}$ and \\ Workineh $\mathrm{W}^{2}$ \\ ${ }^{1}$ Woldia University, Ethiopia \\ ${ }^{2}$ Bahir Dar University, Ethiopia \\ ${ }^{3}$ Gondar Regional Agricultural Research Center, Ethiopia
}

Submission: September 19, 2017; Published: October 17, 2017

*Corresponding author: Solomon Tsegaye, Woldia University, College of Agriculture, P.O. Box 400, Woldia, Ethiopia, Tel: +251913 733 048;

Email: solomontsegaye25@gmail.com; 2008simegn@gmail.com

\begin{abstract}
A cross-sectional study was conducted to know fasciolosis prevalence in cattle plus identifying the risk factors associated in and around Zenzelma town, Bahir Dar Zuriaworeda, west Gojam administration Zone. The study was done in 2016. Parasitological examination of feaces collected from 192 cattle and examined using fecal sedimentation technique to understand fasciolosis prevalence was done. The study observed $26 \%$ prevalence at the study area. Associated predisposing factors taken are; site, sex, breed and age did not show a significant effect for the infection to occur $(\mathrm{P}>0.05)$. However, there was a statistically significant association of fasciolosis between body condition of cattle's $(\mathrm{P}<0.05)$ in which $38.8 \%, 27.3 \%$ and $10.2 \%$ of prevalence obtained in poor, medium, and good body conditions respectively. It was noticed that a highest prevalence rate of $38.8 \%$ was recorded in poor body conditioned animals. The study observed that the incidence of the infection was varying between study sites (i.e. $28.7 \%, 22.1 \%$ ) in Gediro and Sifatra respectively. The current finding shows that fasciolosis in cattle is among the most economically important parasitic disease affecting cattle and common in areas around Bahir Dar. Hence, control strategies should be designed to minimize the occurrence of the infection.
\end{abstract}

Keywords: Cattle; Coprology; Zenzelma; Fasciolosis; Prevalence; Risk factor

\section{Introduction}

Ethiopia have the largest livestock population in Africa, of roughly 53.99 million animals out of this total cattle population, the female cattle constitute about $55.48 \%$ and the remaining $44.52 \%$ are male cattle CSA [1]. However, this great potential is not properly used as a result of disease, malnutrition and other management problems.

Parasitism is amongst the major concerns for the development of livestock sector in tropics [2]. Fasciolosis is one of veterinary important parasitic diseases of ruminants' caused by digenean trematodes of the genus Fasciola commonly referred as liver flukes. As etiological agents, Fasciola gigantica and Fasciola hepatica are the common species of fasciola [3]. Fasciolosis may infect all domestic animals, human and many wild species, but of economical important in sheep and cattle [4].
It has direct economic impact in increasing condemnation of liver, but far more effects are decreased animal productivity, lower calf birth weight and reduced growth in infected animals and cost of animal treatment [5]. The spread of the disease largely depends on the intermediate host's ecology (genus Lymnaea). Lymnaea natalensis, aquatic snails is important for $F$. gigantica whereas L. truncatula, an amphibious snail with wide distribution throughout the world, is an intermediate host for $F$. hepatica.

Temperature of $10^{\circ} \mathrm{C}$ or above is necessary for both snails to breed and for the development of parasite [6]. In Ethiopia, $F$. hepatica and F. gigantica infections occur in areas above 1800 m.a.s.l, and below 1200 m.a.s.l, respectively which has been attributed to variations in the climatic and ecological conditions such as rainfall, altitude and livestock management system. 
Between these altitude limits, both species exist and mixed infections prevail [7].

The life cycle of both species is typical of digenetic trematodes characterized by indirect life cycles [8]. Highlands contain more of water logged marshy areas, provide suitable habitat all the year for snail multiplication. Prophylactic programs based on local epidemiological information are needed for good control strategies in Ethiopia [7]. Therefore, the objective of this study was:

- To estimate the occurrence status of fasciolosis in cattle in and around the study area

- Identifying risk factors associated with fasciolosis in bovine

\section{Materials and Methods}

\section{Study area description}

The study was conducted in and around Zenzelma town, Bahir Dar zuriaworeda, and west Gojam administrative zone. Bahir Dar is the capital city of Amhara regional state that is found $565 \mathrm{~km}$ distance from the capital city of Ethiopia (Addis Ababa) with an altitude $1500-2600$ m.a.s.l. It is located between $12 * 29$ ' N latitude and $37^{*} 29^{\prime} \mathrm{E}$ longitude and annual average rainfall and temperature ranges $1200-1600 \mathrm{~mm}$ and $8-31^{\circ} \mathrm{C}$. $70 \%$ of the land is covered by plain platues, various bush types, low weeds mainly ever green landmasses planted with major agricultural products on some semi humid highlands. Woredas around the city has around 152,772 livestock population in which $(121,470$ cattle, 14,322 sheep, 9,141 goats and 7,839 equines, 36,666 poultry) [9].

\section{Study animals}

The study animals were cattle that found in the selected areas around Zenzelma (Gediro and Sifatra). The cattle include both cross and local breeds. A total of 192 cattle of all age groups and both sexes are randomly selected on the areas where they are grazing in the two different origins. Average cattle age is determined using dentition and classified as young and adult [10]. The scores for body conditions of cattle were recorded from previous study [11].

\section{Study Design}

A cross-sectional study design was used to study fasciolosis prevalence in the faces of cattle and the risk factors associated to the disease around Zenzelma from April 2016 to June, 2016. The risk factors considered for the study were Breed, age, sex, site and body condition.

\section{Data collection and sample size}

The sample size was calculated using the formula given by Thrusfield M [12], 95\% confidence interval with 5\% precision and $19.2 \%$ expected prevalence was used [13]. Fecal samples were collected from 192 cattle by random sampling method. Fresh fecal samples were collected by inserting two fingers directly to the rectum of cattle using disposable plastic gloves and placed in clean screw capped universal bottles. Each sample was labeled with date of submission, age, sex, body condition and place of origin. Samples were preserved with $10 \%$ formalin solution to avoid the eggs development and hatching. Samples that were not processed within 24 hour were stored in a refrigerator at four degree centigrade until all fecal bottles are processed and examined. Sedimentation technique was used to detect fluke eggs by taking $3 \mathrm{~g}$ of fecal sample from each bottle, adding $45 \mathrm{ml}$ of water, thoroughly mixing and straining to remove extra debris material. Dropping a small drop of the sediment on the microscopic slide and identifying fasciola egg from other fluke eggs and methyl blue is used to distinguish Paramphistomum and Fasciola eggs having similar shapes.

\section{Data Analysis}

The collected data was entered and stored into Microsoft Excel spread sheet 2007. The data were thoroughly screened for errors and properly coded before subjecting to statistical analysis. The data were imported from the Microsoft Excel and analyzing using Statistical Package for Social Sciences (SPSS) software version 16.0. Descriptive statistics was used to quantify the prevalence of fasciolosis. Chi-square test used to assess the association of the potential risk factors like age, sex, body condition, breed and site for the occurrence of the fasciolosis. A 5\% significance level was used to know whether there are significant differences or not.

Results

From a total of 192 fecal samples taken from cattle for chorological examination 50 cattle were found infected with fasciolosis. The overall prevalence of fasciolosis in bovine was $26.0 \%$. The prevalence of fasciolosis has no statistically significant difference associated with the study site as indicated in Table 1.

Table 1: Prevalence of fasciolosis in different sites.

\begin{tabular}{|c|c|c|c|c|c|}
\hline \multirow{2}{*}{ Site } & \multicolumn{2}{|c|}{ Laboratory Result } & \multirow{2}{*}{ Total } & \multirow{2}{*}{$\begin{array}{c}\text { Chi- } \\
\text { square }\end{array}$} & $\begin{array}{c}\text { P- } \\
\text { value }\end{array}$ \\
\cline { 2 - 3 } & Positive & Negative & & & \\
\hline Gediro & $33(28.7 \%)$ & $82(71.3 \%)$ & $115(100.0 \%)$ & \multirow{2}{*}{1.049} & 0.306 \\
\hline Sifatra & $17(22.1 \%)$ & $60(77.9 \%)$ & $77(100.0 \%)$ & & \\
\hline Total & $50(26.0 \%)$ & $142(74.0 \%)$ & $192(100.0 \%)$ & & \\
\hline
\end{tabular}

Table 2: Prevalence of fasciolosis with age groups.

\begin{tabular}{|c|c|c|c|c|c|}
\hline \multirow{2}{*}{ Age } & \multicolumn{2}{|c|}{ Laboratory result } & \multirow{2}{*}{ Total } & $\begin{array}{c}\text { Chi- } \\
\text { square }\end{array}$ & $\begin{array}{c}\text { P- } \\
\text { value }\end{array}$ \\
\cline { 2 - 4 } $\begin{array}{c}<4 \\
\text { years }\end{array}$ & $14(21.5 \%)$ & $51(78.5 \%)$ & $65(100.0 \%)$ & & \\
\hline $\begin{array}{c}4-8 \\
\text { years }\end{array}$ & $26(29.5 \%)$ & $62(70.5 \%)$ & $88(100.0 \%)$ & \multirow{2}{*}{1.249} & 0.536 \\
\hline $\begin{array}{c}>8 \\
\text { years }\end{array}$ & $10(25.6 \%)$ & $29(74.4 \%)$ & $39(100.0 \%)$ & & \\
\hline \begin{tabular}{c} 
Total \\
\hline$y y n n n$
\end{tabular} & $50(26.0 \%)$ & $142(74.0 \%)$ & $192(100.0 \%)$ & & \\
\hline
\end{tabular}


This study was also conducted comparison on the effect fasciolosis among different age groups but no statistically significant difference was observed on the prevalence of fasciolosis as indicated in Table 2.

The study samples included both local and cross breeds to compare if there is a variation in prevalence among the breeds but no statistically significant difference was observed on the prevalence of fasciolosis among animals of the different breeds as indicated in Table 3.

Table 3: Prevalence of fasciolosis with breed.

\begin{tabular}{|c|c|c|c|c|c|}
\hline \multirow{2}{*}{ Breed } & \multicolumn{2}{|c|}{ Laboratory Result } & \multirow{2}{*}{ Total } & $\begin{array}{c}\text { Chi- } \\
\text { square }\end{array}$ & $\begin{array}{c}\text { P- } \\
\text { value }\end{array}$ \\
\cline { 2 - 3 } & Positive & Negative & & & \\
\hline Local & $31(24.8 \%)$ & $94(75.2 \%)$ & $125(100.0 \%)$ & \multirow{2}{*}{0.287} & 0.592 \\
\hline Cross & $19(28.4 \%)$ & $48(71.6 \%)$ & $67(100.0 \%)$ & & \\
\hline Total & $50(26.0 \%)$ & $142(74.0 \%)$ & $192(100.0 \% 0$ & & \\
\hline
\end{tabular}

In this study, animals with poor, medium and good animals were among the sample animals. The comparison indicated that there was a significant difference of the disease among animals of different body condition $(\mathrm{P}<0.05)$ as shown in Table 4 .

Table 4: Prevalence of fasciolosis with body condition.

\begin{tabular}{|c|c|c|c|c|c|}
\hline \multirow{2}{*}{$\begin{array}{c}\text { Body } \\
\text { Condition }\end{array}$} & \multicolumn{2}{|c|}{ Laboratory Result } & \multirow{2}{*}{ Total } & \multirow{2}{*}{$\begin{array}{l}\text { Chi- } \\
\text { square }\end{array}$} & \multirow{2}{*}{$\begin{array}{c}\text { P- } \\
\text { value }\end{array}$} \\
\hline & Positive & Negative & & & \\
\hline Poor & $28(38.8 \%)$ & $41(61.2 \%)$ & $\begin{array}{c}67 \\
(100.0 \%)\end{array}$ & \multirow{3}{*}{13.437} & \multirow{3}{*}{0.001} \\
\hline Medium & $18(27.3 \%)$ & $48(72.7 \%)$ & $\begin{array}{c}66 \\
(100.0 \%)\end{array}$ & & \\
\hline Good & $6(10.2 \%)$ & $53(89.3 \%)$ & $\begin{array}{c}59 \\
(100.0 \%)\end{array}$ & & \\
\hline Total & $50(26.0 \%)$ & $142(74.0 \%)$ & $\begin{array}{c}192 \\
(100.0 \%)\end{array}$ & & \\
\hline
\end{tabular}

Sex was another factor studied with the prevalence of fasciolosis but no statistically significant difference was observed on the prevalence of fasciolosis associated with sex category in this study (Table 5).

Table 5: Prevalence of fasciolosis with sex.

\begin{tabular}{|c|c|c|c|c|c|}
\hline \multirow{2}{*}{ Sex } & \multicolumn{2}{|c|}{ Laboratory Result } & \multirow{2}{*}{ Total } & $\begin{array}{c}\text { Chi- } \\
\text { square }\end{array}$ & $\begin{array}{c}\text { P- } \\
\text { value }\end{array}$ \\
\cline { 2 - 4 } & Positive & Negative & & \multirow{2}{*}{0.5} & 0.48 \\
\hline Male & $30(28.0 \%)$ & $77(72.0 \%)$ & $107(100.0 \%)$ & \\
\hline Female & $20(23.5 \%)$ & $65(76.5 \%)$ & $85(100.0 \%)$ & & \\
\hline Total & $50(26.0 \%)$ & $142(74.0 \%)$ & $192(100.0 \%)$ & & \\
\hline
\end{tabular}

\section{Discussion}

The total prevalence is high and it is in line with the report by Amsalu et al., [1] which is $27.22 \%$ around Hawassa city, Yeneneh et al., (2012) with $23.96 \%$ report at Andassa livestock research center. The prevalence is relatively higher than the report made by Yitayal et al., [9] which is $19.2 \%$ in Zenzelma; Ibrahim et al., [14] which is $12.4 \%$ prevalence in Kombolcha; Negesse et al.,
[15] with $15.9 \%$ at Wolega zone and similar $15.9 \%$ prevalence by Tilahun et al., [16] at Nekemte veterinary clinic.

The prevalence in this study was slightly lower than a report by Asmare \& Samuel [17] with 30.02\% prevalence around Dangila but on the other side, the prevalence was far more lower than the previous studies by Yilma \& Mesfin [7] (33.42\%) in North Gondar, Fikirtemariam et al., [18] (36.72\%) around Bahir Dar, Shiferaw et al., [19] (42.25\%) around Assela \& Biniam et al., [20] (41.41\%).

All the above comparisons of the prevalence of fasciolosis in this study with other reports may be associated majorly with the variation in the study seasons. Regardless of the season the difference in management system is another factor for the difference. Factors like agro ecological difference, difference in climatic conditions, presence of favorable condition for the growth of snail in different study areas should also be considered for variation between different reports and relative to this study

Most of earlier research reports indicated that there was a high prevalence of fasciolosis relative to this study and this could be due to a gradual improvement of service delivered by veterinary clinics and veterinarians. In the other hand higher prevalence reports found recently may be associated with study areas which are convenient for the growth of snails like marshy areas. Farmers are also getting good awareness and experience through veterinary extension.

The present report indicated that there was no significant difference among the age groupswhich was the same to the report by Yeneneh and Yitayal et al., [9] and disagree with Solomon \& Abebe [21], Yilma \& Mesfin [22], Asmare \& Samuel [17], Shiferaw et al., [19] and Biniam et al., [20].

There was no significant variation among breed which the same with the result revealed by Yeneneh and different from Yitayal [9], Asmare \& Samuel [17] and Biniam et al., [20]. The difference could be due to unknown blood level of the cross breeds.

The present finding did not show significant difference with the study sites and this report was in line with Yitayal et al., [9] and Asmare \& Samuel [17] however, it was not the same with Fikirtemariam et al., [18]. The reason for this could be due to there was that much difference between the study areas related to favorability for the growth of snails.

The study showed that there was no significant variation among sex of animals which the same with reported by Fikirtemariam et al., [18], Solomon \& Abebe [21], Biniam et al., [20] and disagree with Shiferaw et al.,[19]. The reason that sex is not an associated factor for fasciolosis in this study could be due to the management system is similar for both sexes that means they have equal exposures for contaminated grass and in this study area the management and treatment is the same for all animals. 
There was significant variation between different body conditions of animals which the same with Asmare \& Samuel [17], and it was different from Yitayal et al., [9] and Shiferaw et al., [19]. Infection rate in poor body was higher than medium and good. This could be due to differences in their resistance for concurrent infection and also fasciolosis itself. Concurrent infection and chronic disease on animals with poor body condition may result the animals to be susceptible for fasciolosis [23].

\section{Conclusion and Recommendations}

The present study conducted on prevalence of bovine fasciolosis in and around Zenzelma district indicated that fasciolosis is highly prevalent parasitic disease affecting the health and productivity of animals and body condition is an important risk factor for fasciolosis to occur within cattle. The occurrence is highly associated to the presence of suitable environmental conditions for snails to live and grow. Draining of marshy areas, utilization of swampy areas for crop production, strategic worm control is mandatory.

\section{Acknowledgement}

The authors would like to thank Bahirdar University, especially College of Agriculture and Environmental Sciences veterinary staff members for their material and technical support and special thanks to Fikerabinet Fikadu for his financial support.

\section{References}

1. Amsalu Y, Desta B, Ataro A, Andualem T (2017) Prevalence of Bovine Fasciolosis; Coprological, Abattoir Survey and its Associated Financial Losses Due to Liver Condemnation at Hawassa Municipal Abattoir, Southern Ethiopia. Global Veterinaria 18(2): 124-131.

2. Asmare G, Samuel D (2015) Prevalence of Bovine Fasciolosis and Its associated Risk Factor in and Around Dangila District, Awi Administration Zone, Northwestern Ethiopia. European Journal of Biological Sciences 7(3): 114-119.

3. Asressa Y (2011) Study of prevalence of major bovine fluke infection at Andassa livestock research, North West, Ethiopia, Gondar, Ethiopia Unpublished.

4. Biniam T, Hanna A, Sissay G (2012) Coprological prevalence of bovine fasciolosis in and around woreta, Northwestern Ethiopia. J Vet Med Ani health 4(7): 89-92.

5. Bowman DD, Lynn RC, Eberhard ML, Ana A (2003) Parasitology for veterinarians. $8^{\text {th }}(\mathrm{edn})$, Saunders, New York, p. 115-122.

6. Cringoli G, Rinaldi L, Veneziano V, Capelli G, Malone JB (2002) A cross-sectional coprological Survey from an area of southern Italian Appenninges. Vet Parasito 108: 137-143.
7. CSA (2012) Central Statistical Agency, Federal democratic of Ethiopia, central statistical investigation, statistical abstract.

8. Aregay F, Bekele J, Ferede Y, Hailemelekot M (2013) Study on prevalence of bovine fasciolosis in and around Bahirdar, Ethiopia. Vet J 17(1): 1-11.

9. Hillver GV (2005) Fasciola Antigens as Vaccines against Fascioliasis and schistosomiasis. Journal of Helminthology 79(3): 241-247.

10. Keyyu JD, Kassuku A, Msalilwa L, Monrad J, Kyvsgaard N (2006) Crosssectional prevalence of helminthes infection in cattle on traditional, small-scale and large-scale dairy farms in Iringa district, Tanzania. Veterinary Research Communications 30(1): 45-55.

11. Lotfy WM, El-Morshedy HN, El-Hoda M, El-Tawila MM, Omar EA, et al. (2002) Identification of the Egyptian species of Fasciola. Vet Parasitol 103(4): 323-32.

12. Sissay MM, Uggla A, Waller PJ (2007) Prevalence and seasonal incidence of nematode parasite and fluke infections of sheep and goats in eastern Ethiopia. Trop Anim Health Prod 39(7): 521-531.

13. Negesse MA, Mohammed GA (2014) Prevalence and Economic Significance in Southern Ethiopia. Acta Parasitologica Globalis 5(2): 76-72.

14. Nicholson MT, Butterworth MH (1986) A Guide to condition scoring of zebu cattle. International Livestock Center for Africa, Addis Ababa, Ethiopia, pp.3-29.

15. Nuraddis I, Pawlos W, Tadele T (2009) Prevalence of bovine fasciolosis and Economic Importance Due to Liver condemnation at Kombolcha Industrial Abattoiir, Ethiopia. The Internet Journal of Veterinary Medicine 8(2) pp. 26.

16. Shiferaw M, Feyisa B, Ephrem T (2011) Prevalence of Bovine Fasciolosis and its Economic Significance in and around Assela, Ethiopia. Global Journal of Medical Research 11(3).

17. Solomon W, Abebe W (2007) Effects of a strategy antehelmtic treatment intervention of bovine fasciolosis. A conducted in facilities in endemic area in North West Ethiopia. Vet J 11(2): 59-68.

18. Thrusfield M (2005) Veterinary Epidemiology. $3^{\text {rd }}$ (edn), UK. Blackwell publishing, p. 433

19. Urquhart G, Duncan J, Armour J, Dunn A, Jenning M (1996) Veterinary Parasitology $2^{\text {nd }}(\mathrm{edn})$, Blackwell science, UK, pp. 103-113.

20. Yilma J, Malone J (1998) A geographical information System forecast model for strategic control of fasciolosis in Ethiopia. Vet Parasitol 78(2): 103-27.

21. Yima JM, Mesfin A (2000) Dry season bovine fasciolosis in North Western part of Ethiopia. Revue Med Vet 151(6): 493-500.

22. Yitayal G, Mebratu G, Abebe T (2015) Prevalence of bovine fasciolosis in and around Bahir Dar, North west Ethiopia. Journal of Parasitology and Vector Biology 7(4): 74-79.

23. Tilahun Z, Nemomsa D, Himanot H, Girma K (2014) Study on prevalence of Bovine Fasciolosis at Nekemte Veterinary clinic, East Wolega Zone, Oromia, Ethiopia. European Journal of Biological Sciences 6(2): 40-45. 


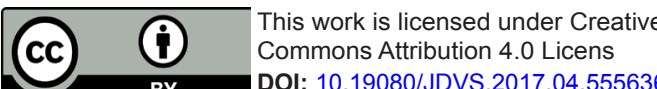
Commons Attribution 4.0 Licens

BY DOI: 10.19080/JDVS.2017.04.555636

\section{Your next submission with Juniper Publishers} will reach you the below assets

- Quality Editorial service

- Swift Peer Review

- Reprints availability

- E-prints Service

- Manuscript Podcast for convenient understanding

- Global attainment for your research

- Manuscript accessibility in different formats

( Pdf, E-pub, Full Text, Audio)

- Unceasing customer service

Track the below URL for one-step submission https://juniperpublishers.com/online-submission.php 